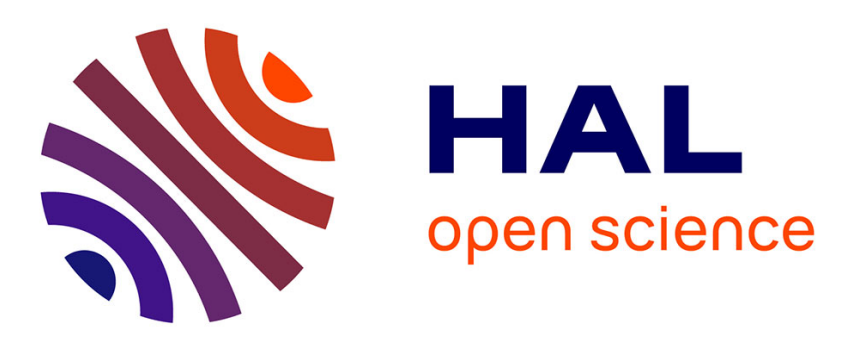

\title{
Helimagnetic structure in diluted Y-Gd alloys
}

\author{
P.J. Brown, R. Caudron, A. Fert, D. Givord, P. Pureur
}

\section{To cite this version:}

P.J. Brown, R. Caudron, A. Fert, D. Givord, P. Pureur. Helimagnetic structure in diluted Y-Gd alloys. Journal de Physique Lettres, 1985, 46 (23), pp.1139-1141. 10.1051/jphyslet:0198500460230113900 . jpa-00232948

\section{HAL Id: jpa-00232948 https://hal.science/jpa-00232948}

Submitted on 1 Jan 1985

HAL is a multi-disciplinary open access archive for the deposit and dissemination of scientific research documents, whether they are published or not. The documents may come from teaching and research institutions in France or abroad, or from public or private research centers.
L'archive ouverte pluridisciplinaire HAL, est destinée au dépôt et à la diffusion de documents scientifiques de niveau recherche, publiés ou non, émanant des établissements d'enseignement et de recherche français ou étrangers, des laboratoires publics ou privés. 
Classification

Physics Abstracts

$75.30-75.25$

\title{
Helimagnetic structure in diluted $\underline{\mathbf{Y}}$-Gd alloys
}

\author{
P. J. Brown $\left({ }^{1}\right)$, R. Caudron $\left({ }^{2}\right)$, A. Fert $\left({ }^{3}\right)$, D. Givord $\left({ }^{4}\right)$ and P. Pureur $\left({ }^{3}\right)$ \\ ( $\left.{ }^{1}\right)$ Institut Laue-Langevin, 156X, 38042 Grenoble Cedex, France \\ ( ${ }^{2}$. ONERA (OM), B.P. 72, 92322 Châtillon Cedex, France \\ (3) Laboratoire de Physique des Solides, Université Paris-Sud, 91405 Orsay Cedex, France \\ $\left({ }^{4}\right)$ Laboratoire Louis Néel, C.N.R.S., 166X, 38042 Grenoble Cedex, France
}

(Reçu le 12 août 1985, accepté sous forme définitive le 10 octobre 1985)

\begin{abstract}
Résumé. - Des études de diffraction de neutrons sur des monocristaux de $\underline{Y}-\mathrm{Gd} 2 \%$ et $3 \%$ révèlent un ordre hélimagnétique en-dessous de la température de Néel, $7 \mathrm{~K}$ et $1 \overline{2} \mathrm{~K}$ respectivement. Une même valeur du vecteur de propagation est obtenue pour les deux échantillons $\left[0,0,0,28 c^{*}\right]$. Les moments de gadolinium sont dans le plan de base de la structure hexagonale. Aucune contribution des électrons de conduction aux amplitudes magnétiques n'apparaît superposée à la contribution 4 f. Le moment du gadolinium à basses températures est d'environ $7 \mu_{\mathrm{B}}$. La variation thermique de l'intensité des satellites magnétiques suit celle prévue par une loi de Brillouin.
\end{abstract}

\begin{abstract}
Neutron scattering studies on $\underline{Y}-\mathrm{Gd} 2$ and 3 at. \% single crystals show a helimagnetic ordering to occur below Néel temperatures of 7 and $12 \mathrm{~K}$ respectively. The same value of the propagation vector $\left[0,0,0.28 c^{*}\right]$ is obtained for both samples. The $\mathrm{Gd}$ moments lie in the basal plane of the hexagonal structure. No contribution from the conduction electrons to the magnetic amplitudes is evidenced in addition to the $4 \mathrm{f}$ contribution. The Gd moment at low temperature is about $7 \mu_{\mathrm{B}}$. The temperature dependence of the magnetic satellite intensity follows that predicted by a Brillouin function.
\end{abstract}

\section{Introduction.}

According to Cable et al. [1], the Y-Gd alloys, at least down to 10 at. \%, exhibit helimagnetic ordering with the helix axis along the hexagonal axis. Spin glass behaviour could be expected to occur at very low Gd concentrations. However, specific heat and magnetization measurements [2-4] suggest that long range magnetic ordering still exists down to $1 \% \mathrm{Gd}$. In order to determine the type of magnetic ordering exactly we have undertaken a neutron scattering study on two single crystals containing 2 and 3 at. \% gadolinium respectively.

\section{Experimental.}

Ingots of $\underline{Y}-$-Gd were obtained by melting the constituents $(99.99 \%$ purity) in a cold crucible. Single crystals were grown by the recrystallization technique at $1380{ }^{\circ} \mathrm{C}$, a temperature close to the HCP-BCC transformation. Crystals of about $0.5 \mathrm{~cm}^{3}$ were isolated. To account for the strong absorption cross section of natural gadolinium for thermal neutrons, $1 \mathrm{~mm}$ thickness slices were cut from the crystals. Neutron experiments were performed on the spectrometer D15 
at I.L.L. The incident wavelength was $0.9 \AA$, in order to minimize the Gd absorption. The samples, after orientation, were placed in a cryostat, the temperature being regulated down to $1.7 \mathrm{~K}$. The extinction was negligible.

\section{Results.}

For both samples, systematic scans in the reciprocal space reveal, satellites, hardly wider than the experimental resolution, which can be indexed as $h \pm \tau$. The value of the wave vector $\tau$ is the same for both samples : $\left[0,0,0.28 c^{*}\right]$. Measurements above the transition temperature revealed a phonon contribution to be superimposed on the reflections $[0,0, l \pm \tau]$, and the data were therefore corrected for this. The larger intensity of magnetic peaks $[0,0,1 \pm \tau]$ compared to the $[h, k, \tau]$ reflections shows that the moment directions are in the basal plane of the hexagonal structure, or very close to it. The magnetic amplitudes in $Y$-Gd $2 \%$ deduced from the intensity of all satellites at $1.7 \mathrm{~K}$, out to $\sin \theta / \lambda=0.4 \AA^{-1}$ are displayed in figure 1 . The $\sin \theta / \lambda$ dependence of the magnetic amplitudes corresponds approximately to that expected for a $4 \mathrm{f} \mathrm{Gd}$ form factor, with a Gd magnetic moment of about $7 \mu_{\mathrm{B}}$. The comparison of this value with the $7.5 \mu_{\mathrm{B}}$ deduced from magnetization measurements suggests the existence of a contribution of about $0.5 \mu_{\mathrm{B}}$ arising from the $5 \mathrm{~d}$ delocalized electrons. The temperature dependence of the $\left[0,0,0.28 c^{*}\right]$ satellite intensity in Y-Gd $3 \%$ is shown in figure 2 . Its decrease as temperature increases was analysed in terms of the squared Brillouin function $\mathfrak{B}_{7 / 2}\left(7 \mu_{\mathrm{B}} H_{\mathrm{m}}(T) / k_{\mathrm{B}} T\right)$, where $H_{\mathrm{m}}(T)$ is the molecular field proportional to the Gd spontaneous magnetization. A good fit to the data is obtained for the value $H_{\mathrm{m}}(0)=68 \mathrm{kOe}$ (Fig. 2).

\section{Discussion.}

The existence of a well-defined helimagnetic structure in Y-Gd has recently been confirmed by an independent neutron experiment [6]. Long-period ordered magnetic structures have also been observed in other yttrium-rare earth alloys [1,5]. It appears that, in all cases, the value of the propagation vector is the same as in $\underline{Y}-\mathrm{Gd}$. The existence of such long range ordered structures down to at least 2 at. $\% R$ atoms in $\underline{Y}-\mathrm{R}$ alloys implies a driving mechanism due to the electronic structure of the $Y$ matrix. It has been proposed $[2,7]$ that the rare earth moments stabilize a spin density wave [8] in the matrix. Another approach considers the generalized susceptibility $\chi(q)$ [9],

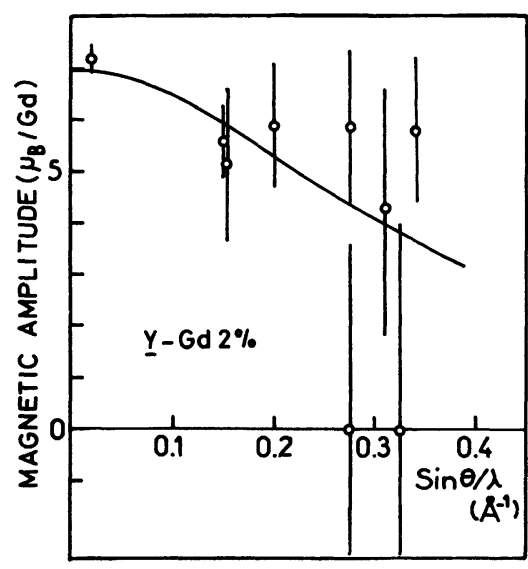

Fig. 1. - Gd magnetic amplitude in $\underline{Y}-\mathrm{Gd} 2 \%$ as a function of $\sin \theta / \lambda$. The full line corresponds to the calculated Gd form factor, with $\mu_{\mathrm{Gd}}=\overline{7} \mu_{\mathrm{B}}$. 


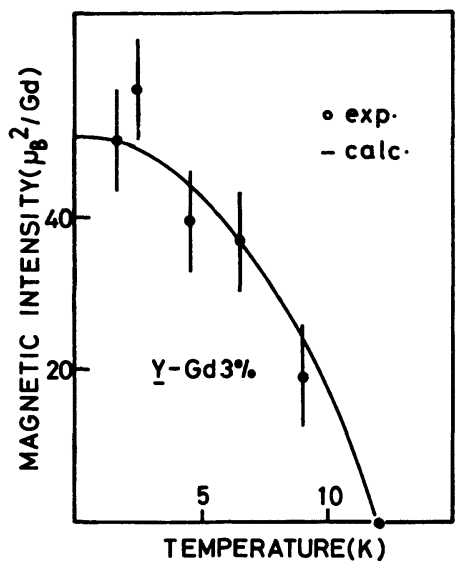

Fig. 2. - Temperature dependence of the $\left[0,0,0.28 c^{*}\right]$ satellite intensity. Full line : calculated variation according to a Brillouin function (see text).

which exhibits a maximum for a nesting vector $q_{0}$ and can induce a helimagnetic order with the spins in the basal plane, as observed experimentally. The $4 \mathrm{~d}$ conduction electrons of the $Y$ matrix are expected to participate in both mechanisms of magnetic coupling described above. This role of the matrix is consistent with the $20 \%$ enhancement of the paramagnetic susceptibility of the alloys [10] with respect to the free ion value. However, in our neutron measurements, the form factor is $4 \mathrm{f}$-like and does not reveal any additional contribution. More accurate measurements of the Gd form factor are required in order to reveal a possible contribution of delocalized electrons.

\section{References}

[1] Child, H. R., Koehler, W. C., Wollan, E. O. and Cable, J. W., Phys. Rev. A 138 (1965) 1655.

[2] Wenger, L. E., Mydosh, J. A., J. Appl. Phys. 55 (1984) 1850.

[3] Levesque, B., Caudron, R. and Costa, P., J. Magn. Magn. Mater. 15-18 (1980) 187.

[4] Pureur, P., Fert, A., Wendler, R. and Baberschke, K., J. Appl. Phys. 57 (1985) 3230.

[5] Rainford, B. D., Stanley, H. B, and Sarkissian, B. V. B., Physica B 130 (1985) 388.

[6] GotaAs, J. A., Rhyne, J. J. and Mydosh, J. A., March Meeting of the Am. Phys. Soc. (1985) p. 532.

[7] Sarkissian, B. V. B. and Coles, B., Commun. Phys. 1 (1976) 17.

[8] Overhauser, A. W., Phys. Rev. Lett. 3 (1959) 414.

[9] Liu, S. H., Gupta, R. P., Sinha, S. K., Phys. Rev. B 4 (1971) 1100.

[10] Pureur, P., Thesis, Orsay, June 1984. 